\title{
In silico characterization of linoleic acid biotransformation to rumenic acid in food derived Lactobacillus plantarum YW11
}

\author{
Tariq Aziz1, Abid Sarwar¹, Muhammad Fahim², Sam Al-Dalali', Zia Ud Din³, Jalal Uddin1, \\ Zou Xin', Zhang Jian'1, Taicia Pacheco Fill'4 and Zhennai Yang1ه
}

1Beijing Advanced Innovation Center for Food Nutrition and Human Health, Beijing Technology and Business University, Beijing, China; ${ }^{2}$ Centre for Omic Sciences, Islamia College Peshawar, KP, Pakistan 25120; ${ }^{3}$ Department of Chemistry Universidade Federeal de Sao Carlos, SP, Brazil; ${ }^{4}$ nnstitute of Chemistry Universidade Estadual de Campinas, SP, Brazil

Lactobacillus plantarum YW11 capability to convert linoleic acid into conjugated linoleic acid and other metabolites was studied in a dose-dependent manner by supplementing LA at different concentrations. L. plantarum YW11 displayed a uniform distinctive growth curve of CLA and other metabolites at concentrations of $L A$ ranging from $1 \%(w / v)$ to $10 \%(w / v)$, with slightly increased growth at higher LA concentrations. The biotransformation capability of L. plantarum YW11 evaluated by GC-MS revealed a total of one CLA isomer, i.e. 9-cis,11-trans-octadecadienoic acid, also known as the rumenic acid (RA), one linoleic acid isomer (linoelaidic acid), and LA metabolites: (E)-9-octadecenoic acid ethyl ester, trans, trans-9,12-octadecadienoic acid, propyl ester and stearic acid. All the metabolites of linoleic acid were produced from 1 to $10 \%$ LA supplemented MRS media, while surprisingly the only conjugated linoleic acid compound was produced at $10 \%$ LA. To assess the presence of putative enzymes, responsible for conversion of LA into CLA, in silico characterization was carried out. The in silico characterization revealed presence of four enzymes (10-linoleic acid hydratase, linoleate isomerase, acetoacetate decarboxylase and dehydrogenase) that may be involved in the production of CLA (rumenic acid) and LA isomers. The biotransformation ability of $L$. plantarum YW11 to convert LA into RA has great prospects for biotechnological and industrial implications that could be exploited in the future scale-up experiments.

Key words: Lactobacillus plantarum YW11, in silico studies, CLA (rumenic acid), LA (stearic acid), $10 \mathrm{LAH}$, linoleate isomerase

Received: 06 December, 2019; revised: 15 January, 2020; accepted: 16 January, 2020; available on-line: 07 February, 2020

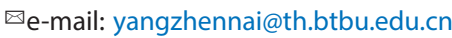

Acknowledgements of Financial Support: Financial support from the Natural Science Foundation of China (No. 31871823) and Beijing Talent Cultivation Quality Construction - First-class Professional Construction (Municipal Level) - Food Science and Engineering (PXM2019 014213 000010) is kindly acknowledged.

Abbreviations: $C L \bar{A}$, conjugated linoleic acid; CFUs, Colony forming units; DC, decarboxylase; $\mathrm{DH}$, dehydrogenase; FAME, fatty acid methyl esters; GC, gas chromatography; GC-MS, gas chromatography and mass spectrometry; El, electron ionization; LA, linoleic acid; 10 LAH, linoleate 10 hydratase; MS, mass spectra; NIST, National Institute of Standard and Technology library

\section{INTRODUCTION}

Conjugated linoleic acid (CLA) refers to positional and geometric isomers of linoleic acid (LA) with one or two double bonds in the cis (c) or trans (t) configuration, separated by simple carbon-carbon (c-c) linkage. CLA iso- mers are naturally occurring trans-fats, commonly found in beef, lamb and dairy products, etc. However, the most abundant and common source of natural CLAs, e.g. rumenic acid, are animal products from ruminal bacteria (Alfaia et al., 2010). Very recently, CLAs have been subject of many research labs owing to its health promoting properties (Yang et al., 2015; Fuke \& Nornberg, 2017), observed both in vitro (O'Hagan \& Menzel., 2003) and in vivo (Wahle $\mathrm{K}$ et al., 2004). Lee and coworkers (Lee et al., 2005) highlighted the potential of CLA that at a relatively low dietary level shows an inhibitory effect against multistage carcinogenesis. Pariza et al., 1987 found some unidentified anti-carcinogenic factors in fried ground beef which were later identified as CLAs. The identified CLAs were effective in inhibiting the chemically induced epidermal carcinogenesis in mice (Pariza et al., 1987).

Additionally, CLA has been reported to reduce the risk of atherogenesis, adipogensis, immune dysfunction (Bhattacharya et al., 2006; Pariza et al., 2004; Roche et al., 2006; Wahle et al., 2004), and have anti-carcinogenesis (Masso-Welch et al., 2004; Lau et al., 2010; Arab et al., 2016), anti-inflammation (Flowers et al., 2009; Olson et al., 2017), anti-diabetic (Castro-Webb et al., 2012; McFarlin et al., 2009; Yuce et al., 2017), anti-obesity (Kim et al., 2010; Gilbert et al., 2011; Martin et al., 2017, de Moraes et al., 2017), as well as bone formation-promoting properties (Jaudszus et al., 2005; Kim et al., 2014). These activities are mainly governed by two major CLA isomers, the rumenic acid $(c), \mathrm{t} 11-\mathrm{C} 18: 2)$ and the t10,c12, c12 CLA isomer (10E, 12Z-linoleic acid), which positively encourage transcriptional or translational control of immunoglobulins, cytokines, lipids (including eicosanoids) and the cell signaling machinery components (Wahle et al., 2004). It is estimated that the intake of CLA in North America is approximately 212 and 151 $\mathrm{mg} / \mathrm{d}$ for men and women, respectively (Lawson et al., 2001), whereas in Germany the intake of CLA is estimated to be approximately 440 and $360 \mathrm{mg} / \mathrm{d}$ for men and women, respectively (Ritzenthaler et al., 2001). These levels are less than the required CLA dietary intake, which is $3.0 \mathrm{~g} / \mathrm{d}$ (Sieber et al., 2004), urging interest in the development of CLA (and especially rumenic acid) enriched foods. Owing to the health promoting activities of rumenic acid, it is necessary to ensure a suitable supply of this isomer by finding a suitable, efficient and low-cost system. The dietary CLA intake might be successfully increased via the use of rumenic acid enriched dairy products, for example a meal containing a serving of high rumenic acid whole milk (460 mg CLA), a sandwich with high rumenic acid butter (365 $\mathrm{mg}$ CLA) and a high rumenic acid cheddar cheese (721 mg CLA) could 
be used to provide $1.546 \mathrm{~g}$ of CLA (Coakley et al., 2003). Such intake of rumenic acid represents more than half of the dose recommended by (lp et al., 1994) and supplied in a manner which might not require large adjustments to human dietary habits. Due to this potential, the rumenic acid has recently attained more attention directed towards identifying strategies for the enrichment of milk with CLA and the development of CLA enriched dairy products. Approaches for naturally enhancing CLA in milk have included management of the lactating ruminants' diet to favor an increased rumenic acid production in the milk, as well as research of CLA producing starter cultures' capabilities.

Several studies have reported that CLA can be produced by microbial metabolism in animals. CLA has shown interaction with microbes, such as lactic acid bacteria or ruminal bacteria, and conversion of the vaccenic acid in the mammary gland (lp et al., 1994). The conversion of LA into CLA occurs naturally in the rumen during bio-hydrogenation of LA (Coakley et al., 2003), though few probiotic strains are capable of the CLA production from free LA added to the medium (Abd E- Salam et al., 2010). Seiber et al., 2004 reported that several strains of Lactobacillus, Lactococcus and Streptococcus have the ability to produce CLA from LA. Subsequently, CLA formation is closely related to the amount of LA, the types and amount of microbes present. Several bacterial strains have been reported so far to convert free linoleic acid (LA) into conjugated linoleic acid (CLA), such as Butyrivibrio fibrisolvens (Kepler et al., 1071), Bifidobacterium breve (Park et al., 2009), B. longum (Barret et al., 2007), Clostridium sporogenes (Verhulst et al., 1985), Lactobacillus reuteri (Lee et al., 2003), L. plantarum (Kishino et al., 2002; Dahiya et al., 2017), L. casei (Alonso et al., 2003), L. acidophilus (Lin et al., 1999), Propionibacterium acnes (Wallace et al., 2007), and P. freudenreichii (Verhuslt et al., 1987). The main CLA isomers documented with the beneficial activities are: cis-9, trans-11 C18:2, trans-10, cis-12 C18:2 and trans-9, trans-11 C18:2 (Yang et al., 2015; Kim et al., 2016; Renes et al., 2017). Among members of the Lactobacillus genus, Alonso and coworkers (Alonso et al., 2003) reported that Lactobacillus acidophilus and Lactobacillus casei were able to covert free LA to CLA. Lee and others (Lee et al., 2007), also reported that Lactobacillus acidophilus, Lactobacillus casei, Lactobacillus delbruechii, Lactobacillus paracasei, Lactobacillus pentosus, Lactobacillus plantarum, Lactobacillus reuteri, Streptococcus salivarius, Bifidobacterium breve, and Bifidobacterium dentium can also produce CLA. On the basis of CLA formation, both the ruminal bacteria and probiotic bacteria, some LAB (such as Lactobacillus or bifidobacterium strains) are capable for the production of CLA (Rodriguez et al., 2012; Rodriguez Alcala et al., 2011; Shingfield et al., 2013; Sorplang et al., 2016), and different enzymes such as the linoleate isomerase, 10-LAH hydratase, oxidoreductase/dehydrogenase and acetoacetate decarboxylase are involved in production of CLA (Yang et al., 2017).

L. plantarum YW11, isolated from the Tibet Kefir, has been found to exhibit antimicrobial, antitumor, antioxidant, and immune regulatory activities (Wang et al., 2015a). L. plantarum YW11 was also shown to produce a ropy acidic EPS, composed of glucose and galactose (molar ratio of 2.71:1) with molecular mass of $1.1 \times 105$ $\mathrm{Da}$, and it had a highly branched-porous microstructure (Wang et al., 2015b). On the basis of these characteristics, strain YW11 is an excellent candidate for applications in functional products. In our previous study, we found that the exopolysaccharide produced by L. plantarum YW11 has multiple bioactivities, including inhibition of pathogen growth, regulation of the microbiota and reducing oxidative status of aged mice. (Jiang Zhang et al., 2017a; Jiang Zhang et al., 2017b). We found that our strain (L. Plantarum YW11) has a potential to produce the CLA isomer (rumenic acid) at 10 percent of LA supplied to the medium.

The aim of the study presented here was to scrutinize and investigate the potential of L. plantarum YW11 to produce CLA and LA isomers. In our previous work we screened six different strains of $L$. plantarum i.e. 1-2, 2-3, $3-2,4-5,12-4$ and $12-5$, for the ability of CLA and LA isomer production, but not one among them was able to produce CLA isomers and stearic acid (Tariq Aziz et al., 2019). Recently, we found that our strain L. plantarum YW11 has the potential to produce the CLA isomer (rumenic acid) as well as the stearic acid.

\section{MATERIALS AND METHODS}

Growth medium for the microorganism. The Lactobacillus plantarum YW11 under investigation in this study was previously isolated from Tibetan kefir grains and kept in the dairy food processing laboratory of Beijing Technology and Business University, Beijing, China. L. plantarum YW11 was activated for 3 times at $37^{\circ} \mathrm{C}$ MRS broth (Beijing Aoboxing Co Ltd) containing 2.0\% glucose, $1.0 \%$ meat extract, $1.0 \%$ tryptone, $0.5 \%$ yeast extract, $0.5 \%$ sodium acetate, $0.1 \%$ Tween $80,0.2 \% \mathrm{~K} 2 \mathrm{H}-$ PO4, $0.2 \%$ diammonium citrate, $0.02 \% \mathrm{MgSO}_{4} \times 7 \mathrm{H}_{2} \mathrm{O}$ and $0.005 \% \mathrm{MnSO}_{4} \times \mathrm{H}_{2} \mathrm{O}$ was used in this study. All of the medium components were dissolved in distilled water, adjusted to $\mathrm{pH} 5.5$ and sterilized at $121^{\circ} \mathrm{C}$ for 15 minutes. The fresh MRS medium, with different concentrations of LA added, was inoculated with $1 \%$ of the activated culture of $L$. plantarum YW11 for growth and production of CLA and LA isomers at $37^{\circ} \mathrm{C}$.

Growth conditions of $\boldsymbol{L}$. plantarum for production of isomers. Growth of $L$. plantarum YW11 was carried out in the MRS medium containing $1 \%, 2 \%, 3 \%, 4 \%, 5 \%, 6 \%$, $7 \%, 8 \% 9 \%$ and $10 \%(\mathrm{w} / \mathrm{v})$ of LA (Shanghai yuanye BioTechnology Co. Ltd). At 0, 8, 16, 24, 36 and 48 h post inoculation, culture samples were taken for determination of viable counts by the plate count method, and expressed by colony forming units (CFUs) per $\mathrm{mL}$, and for determination of CLA and LA isomers as described below.

Extraction of fatty acid from the medium. For analysis by gas chromatography (GC), the culture samples were centrifuged at $1900 \mathrm{rpm}$ for 5 minutes at $4^{\circ} \mathrm{C}$ to remove the cells. An internal standard (C17:0, heptadecanoic acid, 98\% pure; Macklin) was added to $5 \mathrm{ml}$ of the supernatant fluid to obtain a final concentration of $0.15 \mathrm{~g} / \mathrm{ml}$. Next, $5 \mathrm{~mL}$ of isopropanol were added and vortexed for 30 seconds. Afterwards, $2 \mathrm{~mL}$ of isopropanol were added and vortexed for $30 \mathrm{~s}$. Finally, $5 \mathrm{~mL}$ of $n$-hexane were added to this mixture, vortexed for 3 min, incubated for $30 \mathrm{~min}$, and centrifuged at $1900 \mathrm{rpm}$ for $5 \mathrm{~min}$. The upper hexane layer containing fatty acid methyl esters (FAME) was collected and dried under a steam of liquid nitrogen (Shantha et al., 1993)

Gas chromatography and mass spectrometry (GC-MS). For the GC-MS analysis, a Shimadzu GC2010 instrument coupled with a Dual Stage TMP (Ultra) mass spectrometer was used. $2 \mu \mathrm{L}$ of the FAME sample were injected in a split mode, set at 10:1 split ratio at $250^{\circ} \mathrm{C}$. Helium was used as carrier gas at a constant flow rate of $1 \mathrm{~mL} / \mathrm{min}$. The separation was directed on a highly polar (TR-Wax MS, $30 \mathrm{~m}$ length $\times 0.25 \mathrm{~mm}$ i.d. $\times 0.25 \mu \mathrm{m}$ thickness) and fused silica capillary column (Thermo Fisher Scientific). The initial oven temperature was held at $170^{\circ} \mathrm{C}$ for $1 \mathrm{~min}$, 
and then increased at $0.8^{\circ} \mathrm{C} / \mathrm{min}$ to $200^{\circ} \mathrm{C}$. The temperature of line transfer was at $250^{\circ} \mathrm{C}$, and the ion source was controlled at $200^{\circ} \mathrm{C}$. The MS detector was operated at an electron ionization (EI) voltage of $70 \mathrm{eV}$ under a mass scan range of 33-450 amu $(\mathrm{m} / \mathrm{z})$.

Identification and quantitation of CLA and LA isomers. Chemical identification was accompanied by comparison of the mass spectra (MS) of the peaks with those found at the National Institute of Standard and Technology library (NIST, 2014).

Quantitation analysis was done by comparison of their respective peak area with that of the internal standard (i.e. heptadecanoic acid, $50 \mathrm{mg} / 5 \mathrm{~mL}$ of isopropanol). The concentration of each compound was calculated based on the follwing equation:

Concentration of volatiles

$=\frac{\text { peak area of the compound }}{\text { peakea of }}$

peak area of the internal standard $\times$ concentration of the internal standard

All the samples were analyzed in triplicate.

In silico characterization of conversion of LA to CLA and LA isomers by L. plantarum YW11. Enzymes involved in the relevant reactions for conversion of LA to CLA and LA isomers were identified by analysis of the whole genome sequence (GCA_004028295.1) of L. plantarum YW11 using the SWISS-MODEL which is a fully automated protein structure homology modelling server (Biaisini et al., 2014). The protein module was visualized by a protein visualizing program Discovery Studio 3.5 (Dassault Systems BIOVIA, Discovery Studio Modelling Environment 2015). The LA molecule was drawn with ChemSketch v15.0.9 (Chemaxon) assigned with proper $2 \mathrm{D}$ orientation, and the structure of each compound was analyzed for connection error in the bond order. Energy of the molecules was minimized using Avogadro (Hanewell et al., 2012) with MMFF94 force field. Docking studies calculations were performed with the Autodock Tool (Morris et al., 2009). Protein (dehydrogenase) and ligands (LA) structures were converted to the pdbqt file by the MGL Tools 1.5.6 rc3. Interactions of the protein-ligand complex conformations were analyzed using the Autodock Tools 4.2 (Morris et al., 2009) and Discovery Studio 4.1 (Dassault Systems BIOVIA, Discovery Studio Modelling Environment 2015).

Statistical Analysis. Data were statistically analyzed by ANOVA SAS version 9. Evaluation of the signifi-

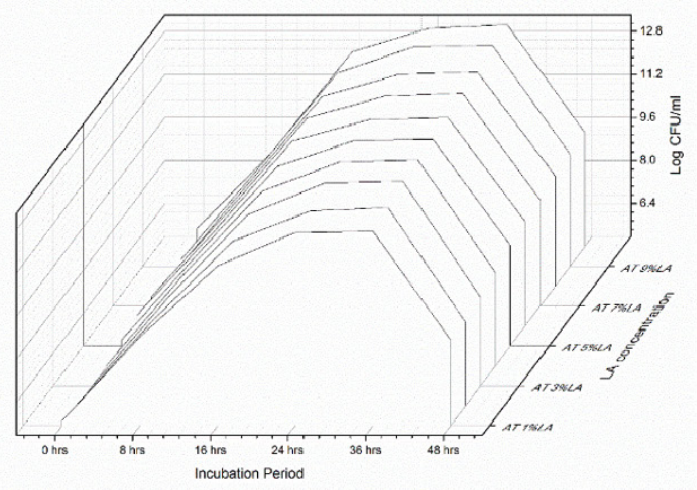

cance of differences between groups was performed with one-way ANOVA as noted in the figure legends.

\section{RESULT AND DISCUSSION}

\section{Growth of L. plantarum YW11 in MRS media under different concentration of LA}

L. plantarum YW11 revealed a characteristic growth curve of typical bacteria at the concentrations of LA ranging from $1 \%(\mathrm{w} / \mathrm{v})$ to $10 \%(\mathrm{w} / \mathrm{v})$, as shown in Fig. 1. For all of the LA concentrations, it was observed that $L$. plantarum YW11 has increased its growth up to $24 \mathrm{~h}$, then entered stationary phase till $36 \mathrm{~h}$, and then the growth decreased till $48 \mathrm{~h}$. There was a slight increase in growth of a strain with the increase of the LA concentrations. On the contrary, many other LAB strains were reported to be inhibited to different extent by LA, and their tolerance to LA varied (Lin et al., 1999; Wallace et al., 2007; Verhuslt et al., 1987). While earlier studies showed that even low LA levels $(25 \mu \mathrm{g} / \mathrm{ml})$ could inhibit bacterial growth (Lin et al., 1999), L. plantarum YW11 was able to grow well at LA concentrations up to $10 \%(\mathrm{w} / \mathrm{v})$, indicating its relatively high tolerance to LA. In order to stop this toxicity of LA, L. plantarum YW11, has shown an ability to enzymatically convert hydrogenated polyunsaturated fatty acids by a mechanism called biohydrogenation which is characterized by a complete reduction of double bonds on the carbon chain, producing non-toxic saturated fatty acids as the final product. Other studies, such as those by (Gorissen et al., 2010; Li et al., 2016), have proposed that LA inhibition is not species but strain dependent. Moreover, Coakley and others (Coakley et al., 2003), reported that all five $L$. renteri strains tested were able to grow with LA up to $1 \mathrm{mg} / \mathrm{mL}$ and, inclusively, three of them tolerated up to $3 \mathrm{mg} / \mathrm{ml}$ of LA.

\section{Identification of CLA, LA isomers, and analogues metabolites by GC-MS}

Gas chromatography-mass spectrometry was used to identify the compounds produced by Lactobacillus plantarum YW11, in the presence of different concentration of LA, ranging from $1 \%$ to $10 \%$. From Table 1 and Fig. 2, it can be seen that 5 compounds were identified by

comparison of their mass spectrum (MS). Four of these compounds were identified as isomers and ana-

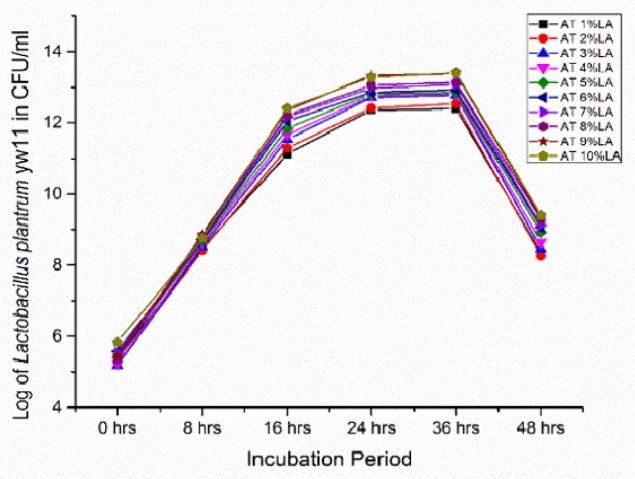

b

Figure 1. (a) CLA and LA isomers and analogues derivatives produced at 8, 16, 24, 36 and $48 \mathrm{~h}$ during growth of $L$. plantarum YW11 at different concentrations of LA in the medium, and (b) Growth pattern of L. plantarum YW11 affected by different concentrations of linoleic acid assessed by the plate count method at $0,8,16,24,36$ and $48 \mathrm{~h}$, respectively. 


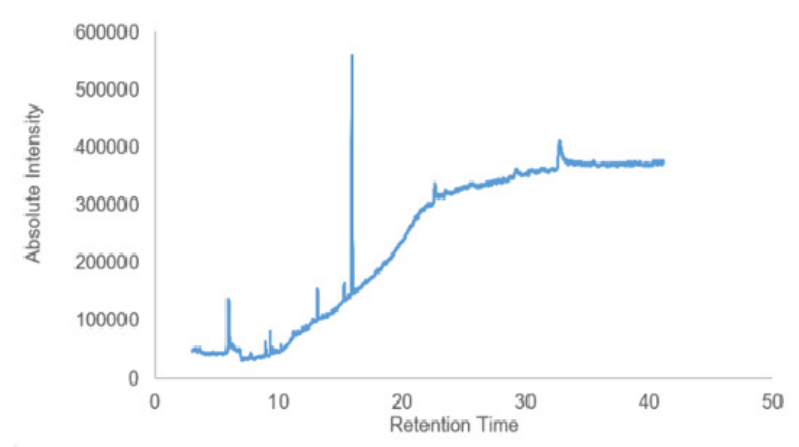

a

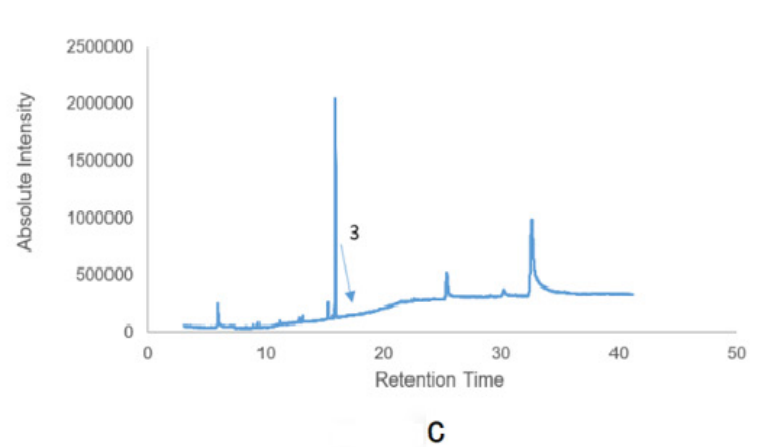

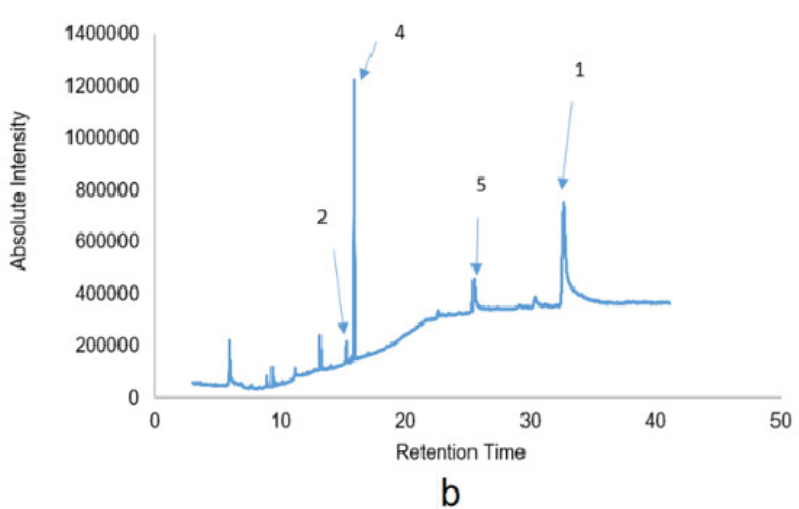

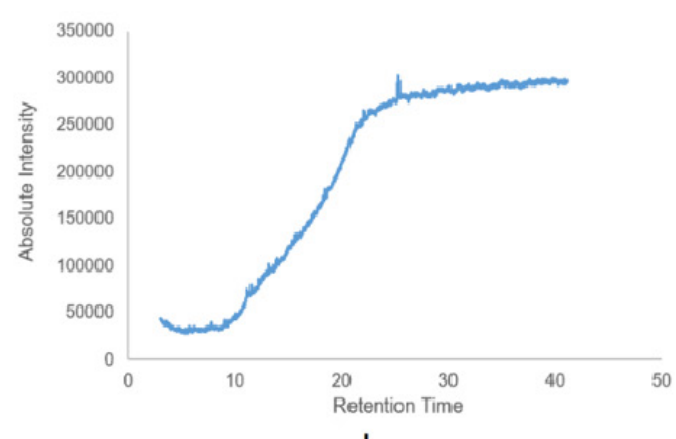

d

Figure 2. Gas chromatography of representative culture samples showing peaks of the LA analogues produced by $L$. plantarum YW11. (a) $1 \%$ of added LA; (b) $5 \%$ of added LA (c) $10 \%$ of added LA, and Control (d) (without LA).

Table 1. GC-MS identification of CLA, LA isomers and derivatives produced by Lactobacillus plantarum YW11 in the presence of a different concentrations of LA.

\begin{tabular}{|c|c|c|c|c|c|c|c|c|c|c|}
\hline \multirow[b]{2}{*}{ Compounds } & \multicolumn{10}{|c|}{ Percentage of LA (\%) } \\
\hline & 1 & 2 & 3 & 4 & 5 & 6 & 7 & 8 & 9 & 10 \\
\hline Linoelaidic acid & - & - & + & + & + & + & + & + & + & + \\
\hline (E)-9-Octadecenoic acid ethyl ester & + & + & + & + & + & + & + & + & + & + \\
\hline 9-cis-11-trans-octadecadienoic acid ( rumenic acid) & - & - & - & - & - & - & - & - & - & + \\
\hline trans,trans-9,12-octadecadienoic acid, propyl ester & + & + & + & + & + & + & + & + & + & + \\
\hline Stearic acid & - & - & + & + & + & + & + & + & + & + \\
\hline
\end{tabular}

+the compound has been produced at this concentration of added LA; - not produced.

logue metabolites of LA, including the linoelaidic acid; (E)-9-octadecenoic acid ethyl ester; trans, trans-9,12octadecadienoic acid, propyl ester; and stearic acid; as shown in Table 1, as well as the (E)-9-octadecenoic acid ethyl ester; trans, trans-9,12-octadecadienoic acid, propyl ester were produced with LA added in the range of $1 \%$ to $10 \%$. However, the remaining two isomers (i.e. the linoelaidic acid and stearic acid) were produced at the range of $3 \%$ to $10 \%$ of added LA, as listed in Table 1. On the other hand, the 9-cis-11-trans-octadecadienoic acid was identified as conjugated LA, and was produced by Lactobacillus plantarum YW11 at 10\% of added LA (see Table 1).

\section{Identification of enzymes involved in the CLA isomer (rumenic acid) production in Lactobacillus plantarum}

As suggested by many researchers in their studies about the presence of multi enzymatic complexes, at least lactobacilli produce conjugated fatty acid by a mechanism that might not only involve the linoleate isomerase (Kishino et al., 2011; Yang et al., 2014; Ortega Anaya et al., 2016). The first step is hydration of LA by $10-\mathrm{LAH}$ resulting in the production of the $10-\mathrm{HOE}$ acid, which is further oxidized by a short chain dehydrogenase $(\mathrm{DH})$, and is subsequently transformed into 10-oxotrans-11 octadecenoic acid by the action of an acetoacetate decarboxylase (DC), and reduced by $\mathrm{DH}$ (10-hydroxy-trans-11-octadecenoic); finally, LAH leads to the production of rumenic acid (RA) and C18:2 t9, $t 11$, as shown in Fig 3.

Figure 3 shows the proposed pathway of rumenic acid production in L. plantarum YW11 by the action of different enzymes, such as $10 \mathrm{LAH}, \mathrm{DH}$ and DC.

In addition, Ortega Anaya and others (Ortega Anaya et al., 2016), have recently reported that in L. plantarum ATCC8014, CLA synthesis takes place due to a multifunctional enolase via dehydration/isomerization of 10-hydroxy-cis-12-octadecenoic acid. 


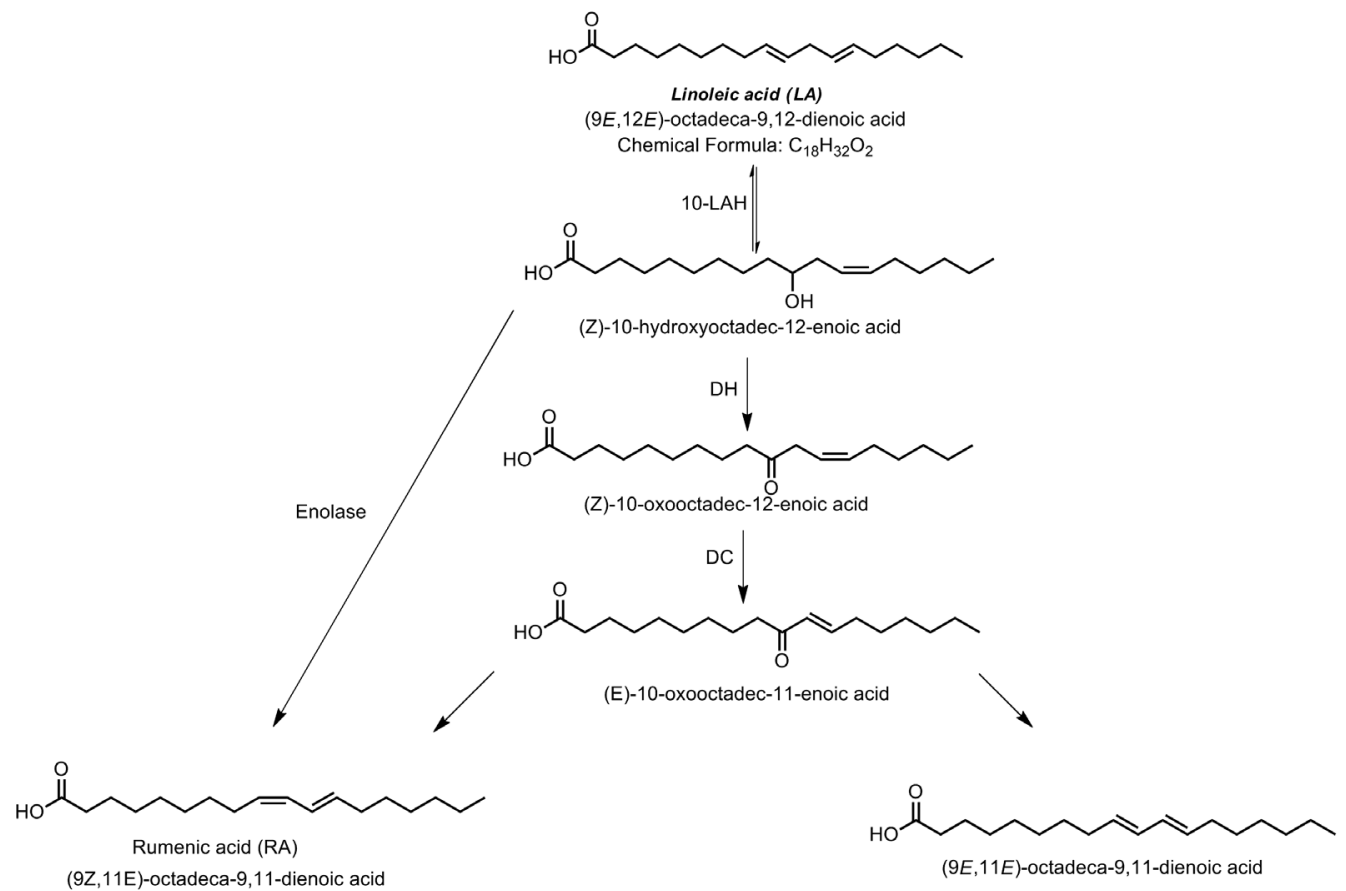

Figure 3. Proposed pathway of rumenic acid production by L. plantarum YW11.

Till now, studies related to the microbial production of hydroxyl fatty acids have been intensively focused on CLA production. However, some of the authors have found that L. plantarum and L. acidopbilus are able to convert LA into 13-hydroxy-cis-9-octadecnoic acid or 10,13-dihydroxy-octadecanoic acid by the action of both 10-LAH and 13-LAH (Yang et al., 2017; Kim et al., 2015).

But till now, the biological importance of such specific compounds for these microorganisms has not been completely understood. However, it has been found that Lactobacillus hammesii (Black et al., 2013) and Lactobacillus plantarum TMW1.460 $\Delta$ lah (Liang et al., 2017) have an antifungal defense mechanism using coriloic acid (13-hydroxy-9,11-otadecadienoic acid).

\section{In silico calculation}

Autodock vina allows flexible docking of ligands into their site of action. It has an ability to use all of the rotatable bonds of the ligands to give a number of conformations from which the best mode could be achieved. On the basis of the binding energy and pharmacological interactions, one can conclude the optimum result. LA has been successfully placed in the cavity of its receptor proteins, the linoleate 10 hydratase (10-LAH), linoleate isomerase, acetoacetate decarboxylase and dehydrogenase. It is evident from in silico calculations that LA has been actively involved in forming a hydrogen bond with the active site residues (Fig. 5, Fig. 6, Fig. 8 and Fig. 9). The main interactions of the protein with the ligand acidic part were observed

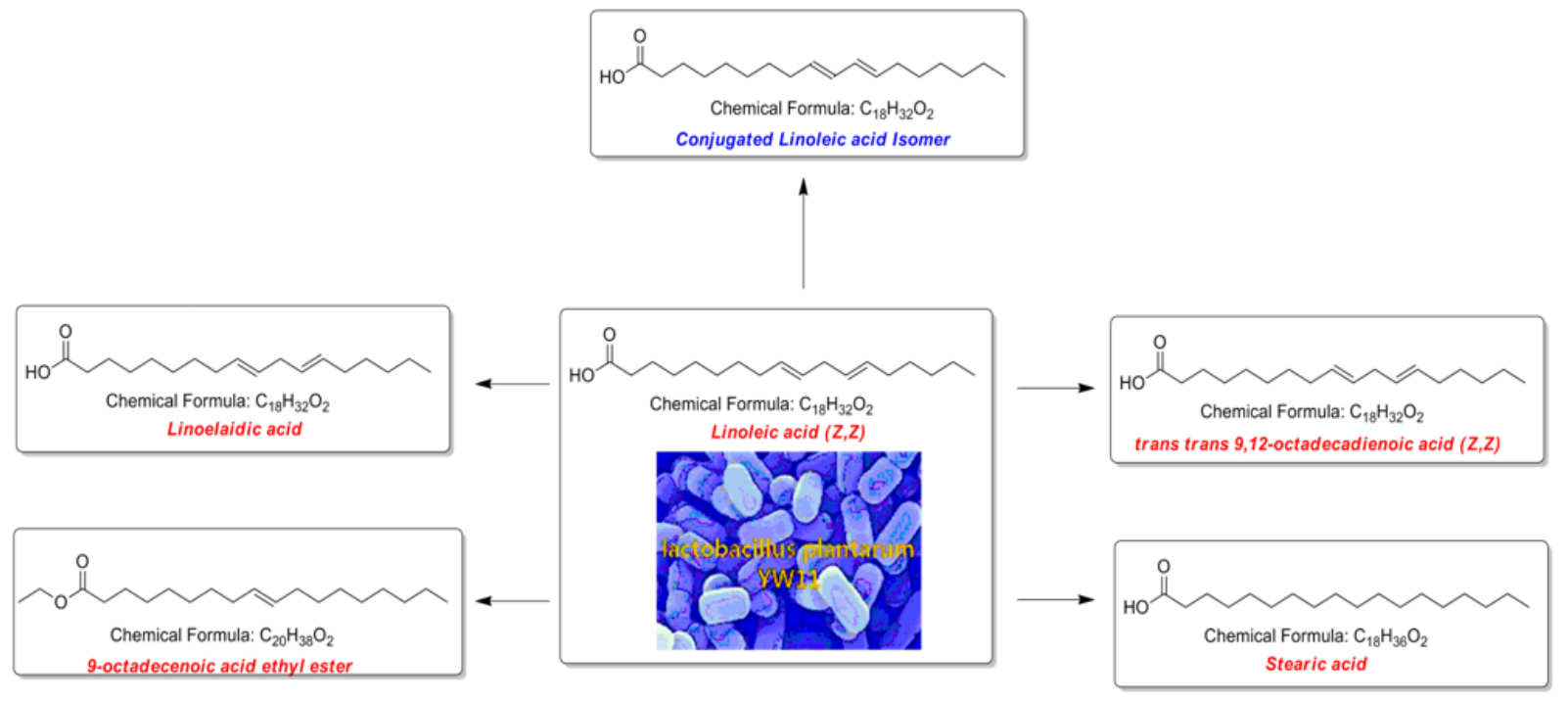

Figure 4. shows the conversion of LA into conjugated linoleic acid (CLA) and other LA derivatives. 
due to the electron withdrawing effect and make a suitable site for the interaction to occur. The overall enzymatic reaction carried out by the whole cell of YW11 is summarized in Fig. 4 below.

Further mechanism and interaction (In-silico studies) are explained below.

\section{The linoleate 10-hydratase (10-LAH)}

Linoleate hydratase belongs to the class of enzymes which are mainly responsible for the formation of an enol form from the adjacent double bonds. This enzyme perfectly holds the ligand molecule for the enzymatic reaction by making hydrogen bonding between the acidic part of LA. The residues involved in the active site are:
Gln-302, Ala-300, Gly-42, Thr-301, Asp-40 and His-41. Among these residues, Gln-302 is involved in the hydrogen bond formation with LA, while the others are involved in the van der waals and electrostatic interactions. The overall 2D and 3D orientation of LA in the active site is represented in Fig. 5 below.

\section{The linoleate isomerase}

Linoleate isomerase belongs to the class of enzymes which are involved in the conversion of one isomeric form of the ligand to another form, through an enzymatic mechanism. Isomers are different forms of the same ligands, having the same molecular formula but a different structural formula with different 3D orientation

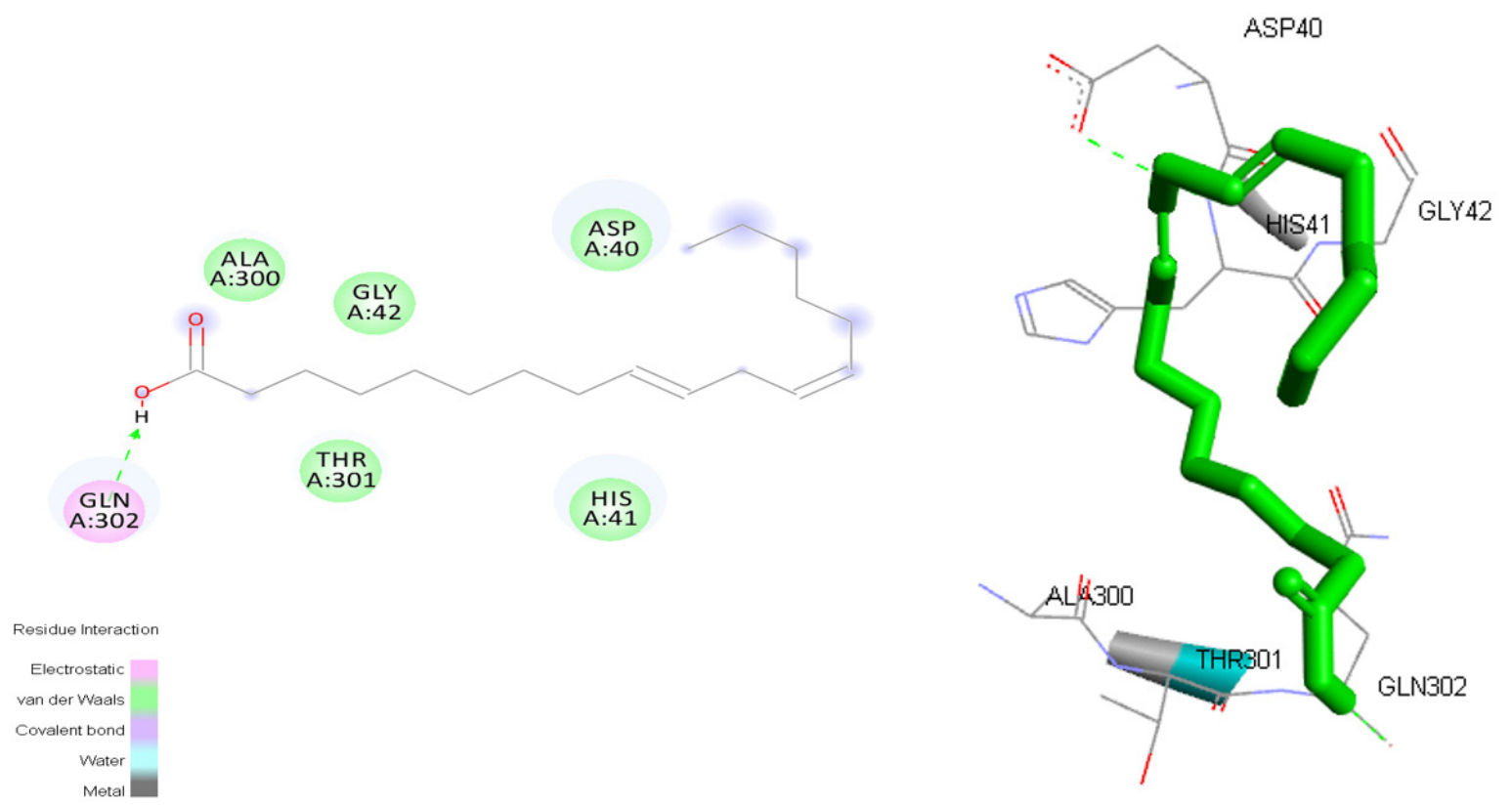

Figure 5. 2D and 3D interaction of linoleate hydratase with LA, showing the 2D and 3D interaction of linoleate hydratase with linoleic acid in L. plantarum YW11.
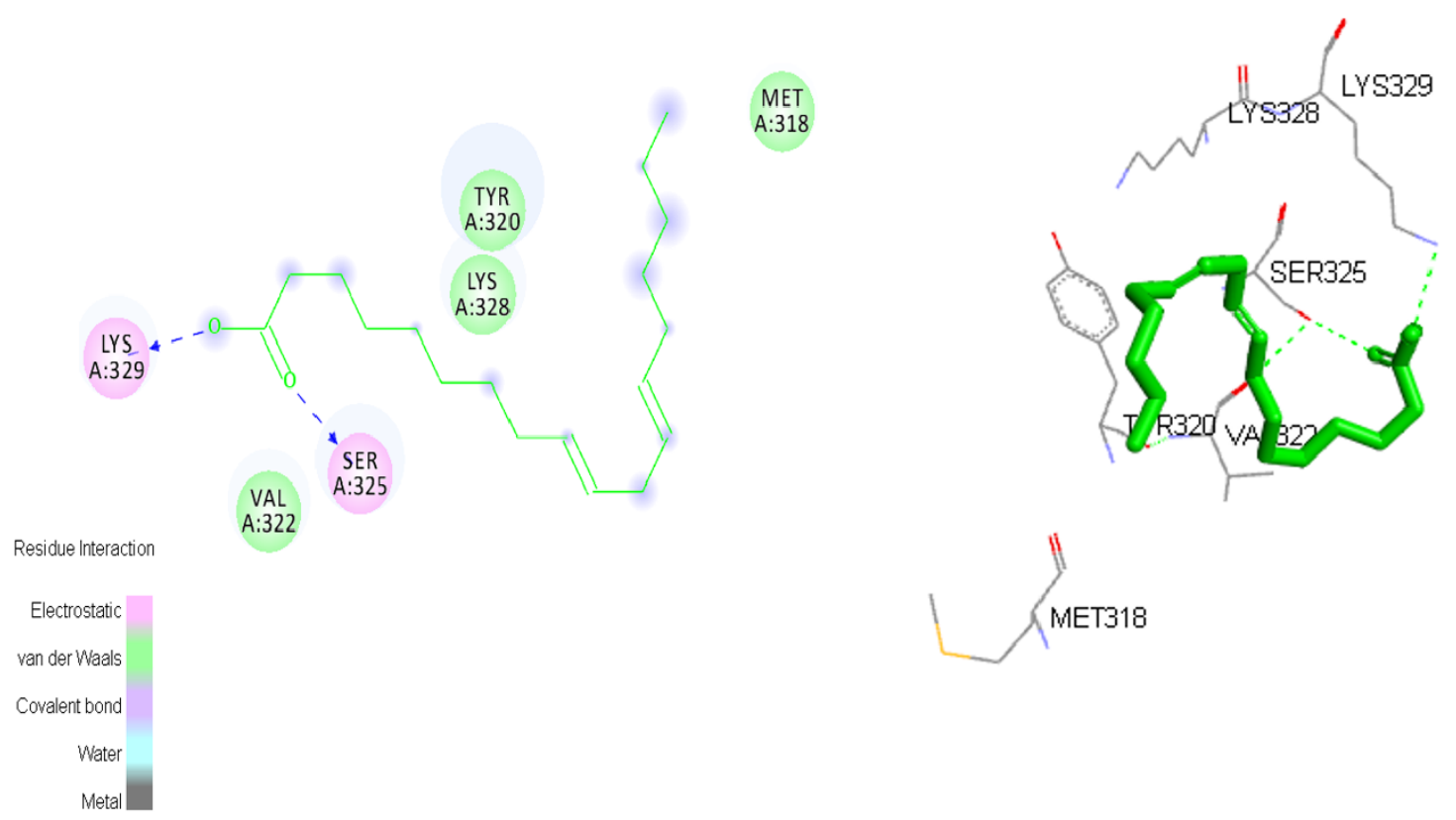

Figure 6. 2D and 3D interaction of LA with linoleate isomerase. 
in space. The genome of Lactobacillus plantarum YW11 was blasted for the search of different linoleate isomerases and gave many hits, among which the best hit was selected for further study.

The conversion of linoleic acid (LA) into CLA and its corresponding isomers was studied by using a computational approach. LA was optimized by using Avogadro and saved into the PDB format. A linoleate isomerase gene was found in Lactobacillus plantarum YW 11 which was blasted by using NCBI platform and then modeled by using the Swiss model. Linoleate isomerase is a monomer protein having a tertiary structure, which consists of its backbone, side chain, hydrophobic moiety, hydrophilic moiety, an acidic group and a basic group. The collective interaction of the linoleate isomerase with LA was carried by using the Auto-dock Vina Program. The optimized structures of linoleate isomerase and linoleic acid was used for the Auto-dock study.

The linoleate isomerase enzyme of YW11 consists of a monomer with active site amino acids including lysine 329 , serine 325, valine 322, tyrosine 320, methionine 318 and lysine 328, as shown in Fig. 9. The hydrogen bond between lysine 329 and LA has a distance of $2.95 \mathrm{~nm}$ while the XDA angle is 97.39, and the DAY angle is 115.76. The second hydrogen bond between serine 325 and LA has the distance of $2.97 \mathrm{~nm}$, and has the XDA angle of 98.73 , and the DAY angle of 165.99 .

Figure 6 shows the 2D and 3D interaction of linoleic acid with the linoleate isomerase enzyme from L. planatarum YW11.

After docking, it was observed that the carboxylic acidic moiety of LA formed two hydrogen bonds with lysine (LYS A:329) and serine (SER:325), and also showed electrostatic and van der waals interactions. As linoleate isomerase is an NADPH dependent enzyme, the hydrogen from NADPH could attack the double bond of LA, and ultimately the reaction of LA with linoleate isomerase and NADPH would lead to the formation of the isomers.

The following table (Table 2) is showing the docking result of LA with linoleate isomerase.

LA show good interaction with active site residues of linoleate isomerase because it occupies the active site which provides the pathway for enzymatic reaction. The acidic group of LA forms two hydrogen bonds, one with lysine 329 (LYS:329) and the other with serine 325 (SER:325). The LA acidic moiety is held by the enzyme by hydrogen and electrostatic interactions, which provides amedium for the double bond transfer reaction.
Table 2. Interaction of LA with linoleate isomerase and theresult calculated by autodock.

\begin{tabular}{lc}
\hline Binding Energy & -0.72 \\
\hline Ligand efficiency & -0.04 \\
\hline Inhibition Constant & $298.31 \mathrm{mM}$ \\
\hline Intermol Energy & -4.44 \\
\hline Vdw_hb_desolv energy & -3.77 \\
\hline Electrostatic energy & -0.67 \\
\hline Total_ internal & -0.39 \\
\hline
\end{tabular}

Table 3. Interaction of LA with acetoacetate decarboxylase, and their result calculated by autodock.

\begin{tabular}{lc}
\hline Binding Energy & -1.14 \\
\hline Ligand efficiency & -0.06 \\
\hline Inhibition Constant & $147.14 \mathrm{mM}$ \\
\hline Intermol Energy & -4.62 \\
\hline Vdw_hb_desolv energy & -3.81 \\
\hline Electrostatic energy & -0.81 \\
\hline Total_internal & -0.63 \\
\hline Calculated RMS & 0.0 \\
\hline
\end{tabular}

\section{The acetoacetate decarboxylase}

Acetoacetate decarboxylase belongs to a class of enzymes which play a key role in solvent production by catalyzing the decarboxylation of acetoacetate moieties, producing acetone and carbon dioxide. The production of solvent acetone by the acetoacetate decarboxylase enzyme containing bacteria was utilized in large-scale industrial syntheses in the first half of the twentieth century. We have explored in this study that beyond this, it also plays an important role in the fatty acid chemistry by converting LA into CLA.

The complete structure of this oligomer consists of twelve monomers. The structure of an oligomer is given below in Fig. 7.

The structure of an individual monomer is reported below along with its major active site for the recognition of LA. The major contributing active site residues consist of amino acids Leu-195, Gly-189, Thr-

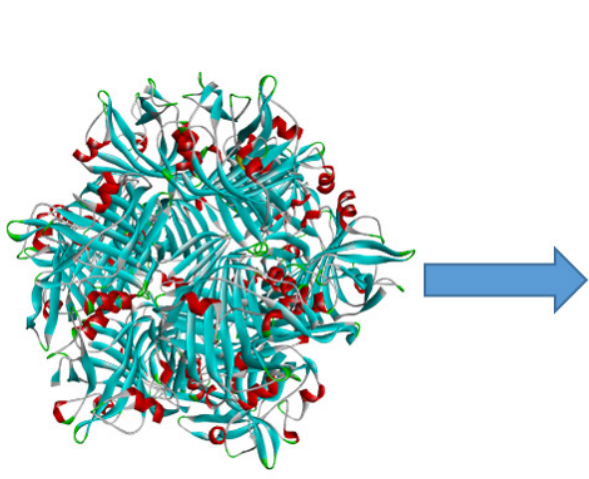

a

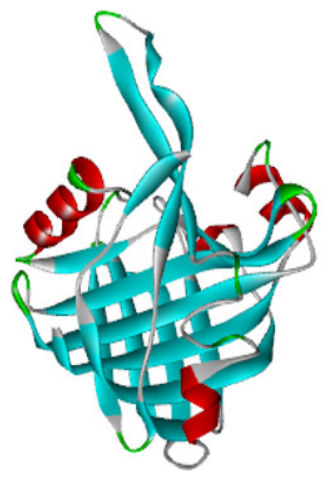

b

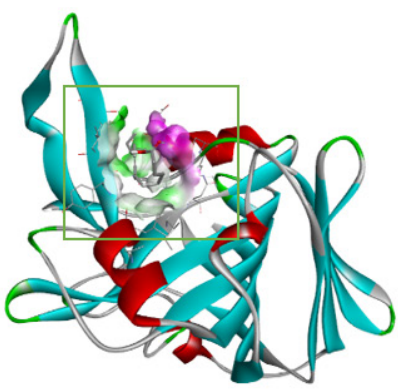

c

Figure 7. (a) the structure of acetoacetate decarboxylase which is an oligomer (b) monomer of acetoacetate decarboxylase and (c) its active site residues. 


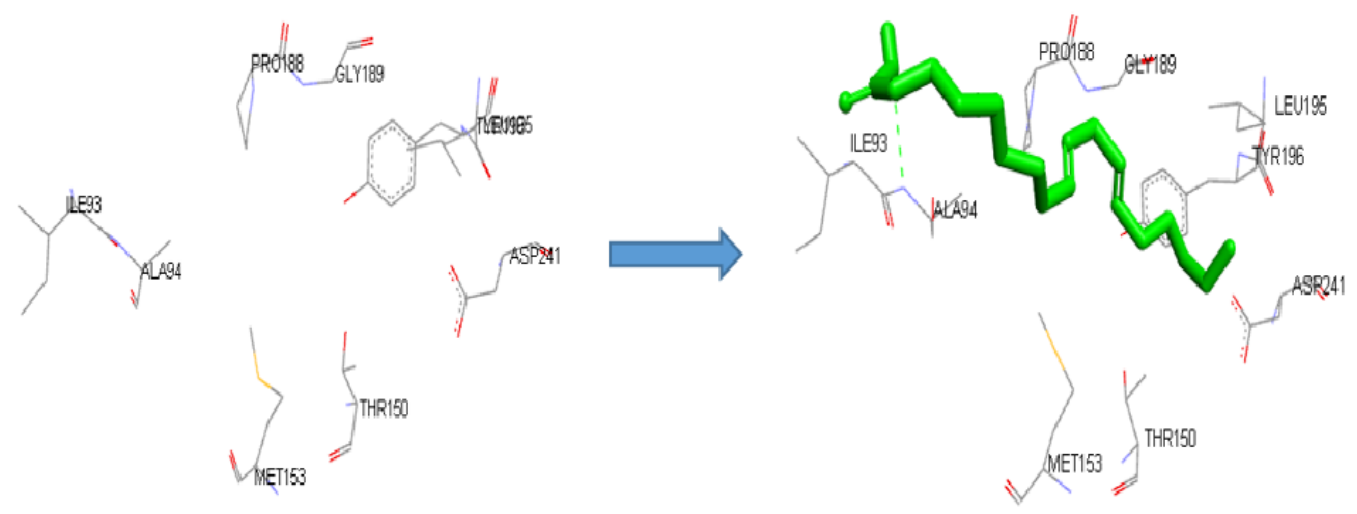

Figure 8. Active site of acetoacetate decarboxylase, and substrate (LA) in that site.

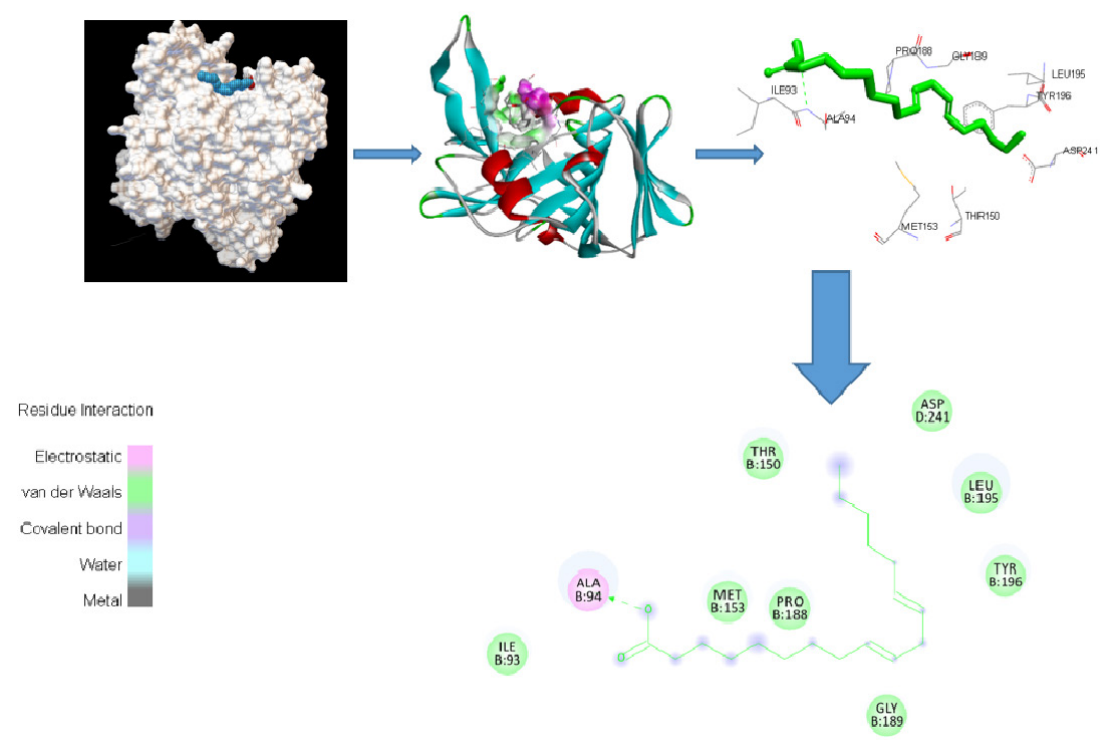

Figure 9. The overall interaction of LA with active site amino acids of Lactobacillus plantrum YW11 acetoacetate decarboxylase

150, Pro-188, Met-153, Ala-94, Ile-93 and Tyr-196 is shown in Fig. 8 and the docking results has been shown in Table 3 as well as the overall interaction has been shown in Fig. 9.

\section{Dehydrogenase/Oxidoreductase:}

Dehydrogenase belongs to a class of enzyme that catalyze a reaction which involves the transfer of electrons from one molecule, the reductant, also called the electron donor, to another, the oxidant, also called the electron acceptor. Thus, these enzymes usually involve the transfer of charge from the catalyzing molecule leading to oxidation or reduction. This group of enzymes usually consists of $\mathrm{NADP}$ or NAD+ dependent enzymes which use it as cofactors. The L. plantarum YW11 dehydrogenase is a tetramer, composed of monomers A, B, C and D. The active site residues and substrate are reported in Figs. 10 and 11 . The amino acids in the active site are Tyr-206, Phe-18, Gly-17, His-16, Met-186, Cys187, Val-141, Ala-91, Gly-92, Lys-160, Tyr-156, Ile-93, Ala-94, Ala-62 and Asn-90. The Tyr-156 amino acid in the active site of dehydrogenase forms a hydrogen bond with the substrate (LA), which provides the plane form for the enzymatic reaction by holding the acidic moiety of substrate for the reduction reaction.
Table 4. Interaction of LA with dehydrogenase/oxidoreductase, and their result calculated by autodock.

\begin{tabular}{lc}
\hline Binding Energy & -1.64 \\
\hline Ligand efficiency & -0.08 \\
\hline Inhibition Constant & $262.68 \mathrm{mM}$ \\
\hline Intermol Energy & -4.98 \\
\hline Vdw_hb_desolv energy & -5.29 \\
\hline Electrostatic energy & 0.31 \\
\hline Total_internal & -0.78 \\
\hline Calculated RMS & 0.0 \\
\hline
\end{tabular}

As these enzymes are cofactor dependent enzymes, hydrogen from the FADH or NADPH could attack the unsaturated moiety of LA which results in formation of a reduced product. Moreover, the docking result is reported in Table 4 .

\section{CONCLUSION}

We show that L. plantarum YW11 is capable of converting LA to a CLA isomer (rumenic acid), and an LA 

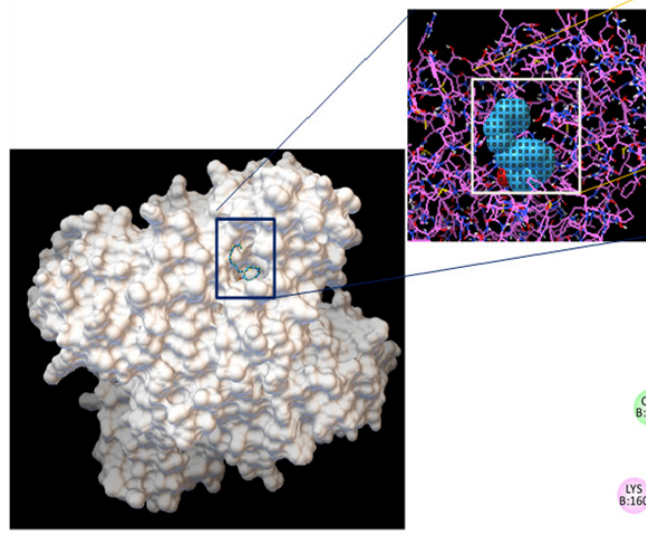

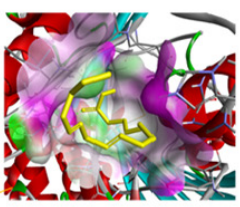<smiles>C1CCCCC1</smiles>

$\underset{\substack{M \in \\ 8: 186}}{\sin }$

TYR

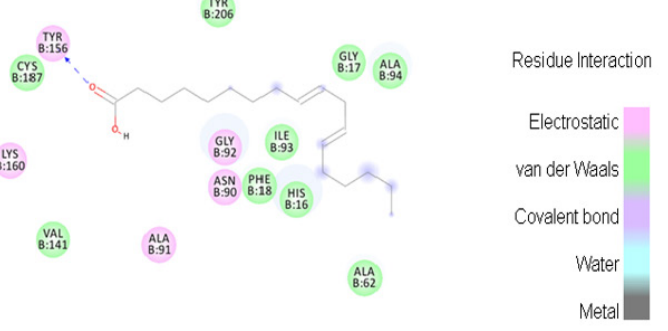

Figure 10. Showing all the enzymatic reactions of dehydrogenase in YW11.

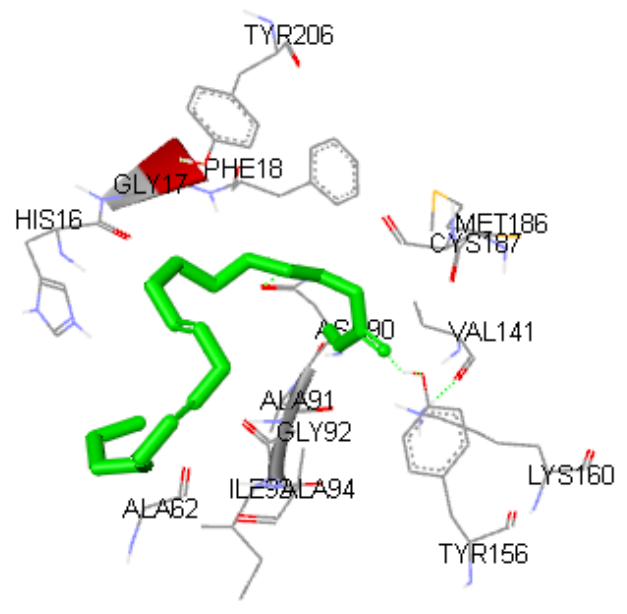

Figure 11. Active site of dehydrogenase with bound substrate (LA).

isomer (such as the linoelaidic acid) and other derivatives of LA: (E)-9-Octadecenoic acid ethyl ester; trans, trans-9,12-Octadecadienoic acid, propyl ester; and stearic acid, at different concentrations of LA supplied. The main reactions involved in this biotransformation process comprise of hydration, isomerization, hydrogenation and reduction, as confirmed by our in-silico studies. The enzymes catalyzing these reactions were identified using the whole genome sequence of $L$. plantarum YW11. The 10 LAH enzyme was shown to bind the LA molecule at its active site mainly by formation of hydrogen bonds between the acidic group of LA and the His 41 residue; similarly, the linoleate isomerase showed two hydrogen bonds between the acidic group of LA with lysine 329 and serine 325. For the other two enzymes, the acetoacetate decarboxylase showed hydrogen bonding with alanine 94, and the dehydrogenase showed hydrogen bonding with Tyr 156. It is hence proven that biotransformation of LA into biologically or industrially important compounds by L. plantarum is an important area of research which needs to be explored in order to replace the synthetic reaction, which is either very expensive by chemical means or either not possible to be done by whole cell bacteria. L. plantarum YW11 has shown many health promoting properties and is also capable of producing rumenic acid which has many health benefits, and so this strain should be of great interest in the future for assessing it's in vivo and in vitro biological properties.

\section{Conflicts of Interest}

There is no conflict of interest between the authors.

\section{REFERENCES}

Abd El-Salam MH, El-Shafie K, Sharaf OM, Effat BA, Asem F, ElAasar M (2010) Screening of some potentially probiotic lactic acid bacteria for their ability to synthesis conjugated linoleic acid. Int J Dairy Technol 63: 62-69. https://doi.org/10.1111/j.14710307.2009.00541.x

Alfaia CM, Alves SP, Lopes AF, Femandes MJE, Costa ASH, Fontes CMGA, Castro MLF, Bessa RJB, Prates JAM (2010) Effect of cooking methods on fatty acid, conjugated isomers of linoleic acid and nutritional quality of beef intramuscular fat. Meat Sci 84: 769777. https://doi.org/10.1016/i.meatsci.2009.11.014

Alonso L, Cuesta EP, Gilliland SE Production (2003) of free conjugated linoleic acid by Lactobacillus acidopbilus and Lactobacillus casei of human intestinal origin. J Dairy Sci 86: 1941-1946. https://doi. org $/ 10.3168 /$ jds.S0022-0302(03)73781-3

Arab A, Akbarian SA, Ghiyas vand R, Miraghajani M (2016) The effects of conjugated linoleic acids on breast cancer: A systematic review. Adv Biomed Res 5: 115. https://doi.org/10.4103/2277-9175

Barrett E, Ross RP, Fitzgerald GF, Stanton C (2007) Rapid screening method for analyzing the conjugated linoleic acid production capabilities of bacterial cultures. Appl Environ Microbiol 73: 2333-2337. https://doi.org/10.1128/AEM.01855-06

Bhattacharya A, Banu J, Rahman M, Causey J, Fernandes G (2006) Biological effects of conjugated linoleic acids in health and disease. J Nutr Biochem 17: 789-810. https://doi.org/10.1016/j.jnutbio.2006.02.009

Biasini M, Bienert S, Waterhouse A, Arnold K, Studer G, Schmidt T (2014) SWISS-MODEL: modelling protein tertiary and quaternary structure using evolutionary information., Nucleic Acids Res 42: W252-258. https:// doi.org/10.1093/nar/gku340

Black BA, Zannini E, Curtis JM, Ganzle MG (2013) Antifungal hydroxyl fatty acids produced during sourdough fermentation: microbial and enzymatic pathways and antifungal activity in bread. Appl Environ Microbiol 79: 1866-1873. https://doi.10.1128/AEM.03784-12

Castro Webb N, Ruiz Narvaez EA, Campos H (2012) Cross-sectional study of conjugated linoleic acid in adipose tissue and risk of diabetes. Am J Clin Nutr 96: 175-181. https://doi.org/10.3945/ ajcn.111.011858

Coakley M, Ross RP, Nordgren M, Fitzgerald G, Devery R, Stanton C (2003) Conjugated linoleic acid biosynthesis by human-derived 
Bifidobacterium species. I Appl Microbiol 94: 138-145. https://doi. org/10.1046/j.1365-2672.2003.01814.x

Dahiya DK, Puniya AK (2017) Isolation, molecular characterization and screening of indigenous lactobacilli for their abilities to produce bioactive conjugated linoleic acid (CLA). J Food Sci Technol Mys 54: 792-801. https://doi.org/10.1007/s13197-017-2523-x

Dassault Systèmes BIOVIA, Discovery Studio Modeling Environment, (2015)

de Moraes C, de Oliveira CA, do Amaral MEC, Landini GA, Catisti R (2017) Liver metabolic changes induced by conjugated linoleic acid in calorie-restricted rats. Arch Endocrinol Metab 61: 45-53. https:// doi.org/10.1590/2359-3997000000186

Flowers M, Thompson PA (2009) t10c12 conjugated linoleic acid suppresses HER2 protein and enhances apoptosis in SKBr3 breast cancer cells: possible role of COX2. Plos One. https://doi.org/10.1371/ journal.pone.0005342

Fuke G, Nornberg JL (2017) Systematic evaluation on the effectiveness of conjugated linoleic acid in human health. Cri Rev Food Sci Nutr 57: 1-7. https://doi.org/10.1080/10408398.2012.716800

Gilbert W, Gadang V, Proctor A, Jain V, Devareddy L (2011) Transtrans conjugated linoleic acid enriched soybean oil reduces fatty liver and lowers serum cholesterol in obese Zucker rats. Lipids 46: 961-968. https://doi.org/10.1007/s11745-011-3585-6

Gorissen L, Raes K, Weckx S, Dannenberger D, Leroy F, De Vuyst L, De Smet S (2010) Production of conjugated linoleic acid and conjugated linolenic acid isomers by Bifdobacterium species. Appl Microbiol Biotechnol 87: 2257-2266. https://doi.org/10.1007/s00253010-2713-1

Ha YL, Grimm NK, Pariza MW (1987) Anticarcinogens from fried ground beef: heat-altered derivatives of linoleic acid. Carcinogenesis 8: 1881-1887

Hanwell MD, Curtis DE, Lonie DC, Vandermeerschd T, Zurek E, Hutchison GR (2012) Avogadro: An advanced semantic chemical editor, visualization, and analysis platform. J Cheminform 4: 1-17. https://doi.org/10.1186/1758-2946-4-17.

Ip C, Singh M, Thompson HJ, Scimeca JA (1994) Conjugated linoleic acid suppresses mammary carcinogenesis and proliferative activity of the mammary gland in the rat. Cancer Res 54: 1212-1215

Jaudszus A, Foerster M, Kroegel C, Wolf I, Jahreis G (2005) Cis-9, trans-11-CLA exerts anti-inflammatory effects in human bronc hial epithelial cells and eosinophils: comparison to trans-10, cis-12-CLA and to linoleic acid. Biochim Biophys Acta. 1737: 111-118. https://doi. org/10.1016/j.bbalip.2005.11.001

Zhang J, Zhao W, Guo X, Guo T, Zheng Y, Wang Y, Hao Y, Yang Z (2017) Survival and effect of exopolysaccharide-producing Lactobacillus plantarum YW11 on the physicochemical properties of ice cream. Pol J Food Nutr Sci 67: 191-200. https://doi.org/10.1515/ pifns-2017-0002

Zhang J, Zhao X, Jiang Y, Zhao W, Guo T, Cao Y, Teng J, Hao $\mathrm{X}$, Zhao J, Yang Z (2017) Antioxidant status and gut microbiota change in an aging mousemodel as influenced by exopolysaccharide produced by Lactobacillus plantarum YW11 isolated from Tibetan kefir. J Dairy Sci 100: 6025-6041. https://doi.org/10.3168/jds.201612480

Kepler CR, Tucker WP, Tove SB (1971) Biohydrogenation of unsaturated fatty acids. V. Stereospecificity of proton addition and mechanism of ac tion of linoleic acid 12-cis, $\Delta 11$-trans-isomerase from Butyrivibrio fibrisolvens. J Biol Chem 246: 2765-2771.

Lee KW, Lee HJ, Cho HY, Kim YJ (2005) Role of the conjugated linoleic acid in the prevention of cancer. Crit Rev Food Sci Nutr 45: 135-144. https://doi.org/10.1080/10408690490911800

Kim JH, Pan JH, Park HG, Yoon HG, Kwon OJ, Kim TW (2010) Functional comparison of esterified and free forms of conjugated linoleic acid in high-fat-diet-induced obese C57BL/6J mice. J Agr Food Chem 58: 11441-11447

Kim KR, Oh HJ, Park CS, Hong SH, Park JY, Oh DK (2015) Unveiling of novel regio-selective fatty acid double bond hydratases from Lactobacillus acidophilus involved in the selective oxyfunctionalization of mono- and di-hydroxy fatty acids. Biotechnol Bioeng 112: 2206 -2213. https://doi.org/10.1002/bit.25643

Kim L, Park Y, Park Y (2014) trans-10, cis-12 CLA promotes osteoblastogenesis via SMAD mediated mechanism in bone marrow mesenchymal stem cells. J Funct Foods 8: 367-376

Kim JH, Kim Y, Kim YJ, Park Y (2016) Conjugated linoleic acidpotential health benefits as a functional food ingredient. Ann Rev Food Sci Tech 7: 221-244. https://doi.org/10.1146/annurevfood-041715-033028

Kishino S, Ogawa J, Omura Y, Matsumura K, Shimizu S (2002) Conjugated linoleic acid production from linoleic acid by lactic acid bacteria. J Am Oil Chem Soc 79: 159-163

Kishino S, Park SB, Takeuchi M, Yokozeki K, Shimizu S, Ogawa J (2011) Novel multi-component enzyme machinery in lactic acid bacteria catalyzing CC double bond migration useful for conjugated fatty acid synthesis. Biochem Biophys Res Commun 416: 188-193. https://doi.org/10.1016/j.bbrc.2011.11.022
Lau DS, Archer MC (2010) The 10t,12c isomer of conjugated linoleic acid inhibits fatty acid synthase expression and enzyme activity in human breast, colon, and prostate cancer cells. Nutri Cancer 62: 116-121. https://doi.org/10.1080/01635580903191536.

Lawson RE, Moss AR, Givens DI (2001) The role of dairy products in supplying conjugated linoleic acid to man's diet: a review. Nutr Res Rev 14: 153-173. https://doi.org/10.1079/NRR200121.

Lee S, Kim C, Cho S, Choi H, Ji G, Oh D (2003) Bioconversion of linoleic acid into conjugated linoleic acid during fermentation and by washed cells of Lactobacillus reuteri. Biotechnol Lett 25: 935-938

Lee K, Paek K, Lee HY, Park JH, Lee Y (2007) Antiobesity effect of trans-10, cis-12-conjugated linoleic acid-producing Lactobacillus plantarum PL62 on diet-induced obese mice. J Appl Microbiol 103: 1140-1146. https://doi.org/10.1111/j.1365-2672.2007.03336.x

Li P, Li X, Gu Q (2016) Comparative genomic analysis of Lactobacillus plantarum ZJ316 reveals its genetic adaptation and potential probiotic profiles. J Zhejiang Univ-Sc B 17: 569-579. https://doi. org/10.1631/jzus.B1600176

Liang N, Cai P, Wu D, Pan Y, Curtis JM, Ganzle MG (2017) Highspeed counter-current chromatography (HSCCC) purification of antifungal hydroxy unsaturated fatty acids from plant-seed oil and Lactobacillus cultures. J Agric Food Chem 65: 11229-11236. https:// doi.org/ 10.1021/acs.jafc.7b05658

Lin TY, Lin CW, Lee CH (1999) Conjugated linoleic acid concentration as affected by lactic cultures and added linoleic acid. Food Chem 67: 1-5

Martins SV, Pires VMR, Madeira AP, Nascimento M, Alfaia C, Castro MF (2017) Novel anti-adipogenic properties of the individual trans8, cis10 conjugated linoleic acid (CLA) isomer in 3T3-L1 adipocytes. Euro J Lipid Sci Technol 119: 1600042. https://doi.org/10.1002/ ejlt.201600042

Masso Welch PA, Zangani D, Ip C, Vaughan MM, Shoemaker SF, McGee SO (2004) Isomers of conjugated linoleic acid differ in their effects on angiogenesis and survival of mouse mammary adipose vasculature. J Nutr 134: 299-307. https://doi.org/10.1093/jn/134.2.299

McFarlin BK, Strohacker KA, Kueht ML (2009) Pomegranate seed oil cons umption during a period of high-fat feeding reduces weight gain and reduces type 2 diabetes risk in CD-1 mice. Brit J Nutr 102: 54-59. https://doi.org/10.1017/S0007114508159001

Morris GM, Huey R, Lindstrom W, Sanner MF, Belew RK, Goodsell DS (2009) AutoDock4 and AutoDockTools4: Automated docking with selective receptor flexibility. J Comput Chem 30: 2785-2791. https://doi.org/10.1002/jcc.21256

O'Hagan S, Menzel A (2003) A subchronic 90-day oral rat toxicity study and in vitro genotoxicity studies with a conjugated linoleic acid product. Food Chem Toxicol 41: 1749-1760. https://doi.org/10.1016/ s0278-6915(03)00203-5

Olson JM, Haas AW, Lor J, McKee HS, Cook ME (2017) A comparison of the anti-inflammatory effects of cis- 9 , trans-11 conjugated linoleic acids to celecoxib in the collagen-induced arthritis model. Lipids 52: 151-159

Ortega-Anaya J, Hernandez Santoyo A (2016) Production of bioactive conjugated linoleic acid by the multifunctional enolase from Lactobacillus plantarum. Int J Biol Macromol 91: 524-535. https://doi. org/10.1016/j.ijbiomac.2016.05.105

Pariza MW (2004) Perspective on the safety and effectiveness of conjugated linoleic acid. Am J Clin Nutr 79: 1132S-1136S. https://doi. org/10.1093/ajcn/79.6.1132S

Park HG, Cho SD, Kim JH, Lee H, Chung SH, Kim SB (2009) Characteriz ation of conjugated linoleic acid production by Bifidobacterium breve LMC 520. J Agr Food Chem 57: 7571-7575. https://doi. org/10.1021/jf9014813

Renes E, Linares DM, Gonzalez L, Fresno JM, Tornadijo ME, Stanton C (2017) Study of the conjugated linoleic acid synthesis by Lactobacillus strains and by different co-cultures designed for this ability. J Funct Foods 35: 74-80. https://doi.org/10.1016/j.jff.2017.05.015

Ritzenthaler KL, McGuire MK, Falen R, Shultz TD, Dasgupta N, McGuire MA (2001) Estimation of conjugated linoleic acid intake by written dietary assessment methodologies underestimates actual intake evaluated by food duplicate methodology. J Nutr 131: 15481554. https://doi.org/10.1093/jn/131.5.1548

Roche HM, Noone E, Nugent A, Gibney MJ (2001) Conjugated linoleic acid: a novel therapeutic nutrient. Nutr Res Rev 14: 173-187

Rodrigues D, Rocha Santos TA, Gomes AM, Goodfellow BJ, Freitas AC (2012) Lipolysis in probiotic and synbiotic cheese: The influence of probiotic bacteria, prebiotic compounds and ripening time on free fatty acid profiles. Food Chem 131: 1414-1421

Rodríguez Alcalá LM, Braga T, Malcata FX, Gomes A, Fontecha J (2011) Quantitative and qualitative determination of CLA produced by Bifidobacterium and lactic acid bacteria by combining spectrophotometric and Ag+-HPLC techniques. Food Chem 125: 13731378. https://doi.org/10.1016/j.foodchem.2010.10.008

Shantha N, Decker EA, Henning B (1993) Comparision of methylation methods for the quantification of Conjugated Linoleic Isomer. J AOAC Int 76: 664-649 
Shingfield KJ, Bonnet M, Scollan ND (2013) Recent developments in altering the fatty acid composition of ruminant-derived foods. Animal 7: 132-162. https://doi.org/10.1017/S1751731112001681

Sieber R, Collomb M, Aeschlimann, A, Jelen P, Eyer H (2004) Impact of microbial cultures on conjugated linoleic acid in dairy products A review. Int Dairy J 14: 1-15.

Sornplang P, Piyadeatsoontorn S (2016) Probiotic isolates from unconventional sources: a review. J Anim Sci Technol 58: 26. https://doi. org/10.1186/s40781-016-0108-2

Aziz T, Sarwar A, Al-Dalali S, Ud Din Z, Megrous S, Ud Din J, Zou X, Zhennai Y (2019) Production of linoleic acid metabolites by different probiotic strains of Lactobacillus plantarum. Prog Nutr 21: 693701. https://doi.org/10.23751/pn.v21i3.8573

Verhulst A, Janssen G, Parmentier G, Eyssen H (1987) Isomerization of polyunsaturated long chain fatty acids by propionibacteria. Sys Appl Microbiol 9: 12-15

Verhulst A, Semjen G, Meerts U, Janssen G, Parmentier G, Asselberghs S (1985) Biohydrogenation of linoleic acid by Clostridium sporogenes, Clostridium bifermentans, Clostridium sordellii and Bacteroides sp. FEMS Microbiol Lett 31: 255-259

Wahle KW, Heys SD, Rotondo D (2004) Conjugated linoleic acids: are they beneficial or detrimental to health. Prog Lipid Res 43: 553-587. https://doi.org/10.1016/j.plipres.2004.08.002

Wallace RJ, McKain N, Shingfield KJ, Devillard E (2007) Isomers of conjugated linoleic acids are synthesized via different mechanisms in ruminal digesta and bacteria. J Lipid Res 48: 2247-2254. https://doi. org/10.1194/jlr.M700271-JLR200
Wang J, Zhao X, Tian Z, He C, Yang Y, Yang Z (2015) Isolation and characterization of exopolysaccharide-producing Lactobacillus plantarum SKT109 from Tibet Kefi r. Pol J Food Nutr Sci 65: 269-280. https://doi.org/10.1515/pjfns-2015-0023

Wang J, Zhao X, Tian Z, Yang Y, Yang Z (2015) Characterization of an exopolysaccharide produced by Lactobacillus plantarum YW11 isolated from Tibet Kefi r. Carbohydr Polym 125: 16-25. https://doi. org/10.1016/j.carbpol.2015.03.003

Yang B, Chen H, Gu Z, Tian F, Ross R, Stanton C, Chen Y, Chen W, Zhang H (2014) Synthesis of conjugated linoleic acid by the linoleate isomerase complex in food-derived lactobacilli. I Appl Microbiol 117: 430-439. https://doi.org/10.1111/jam.12524

Yang B, Chen H, Stanton C, Ross RP, Zhang H, Chen YQ (2015) Review of the roles of conjugated linoleic acid in health and disease. $J$ Funct Foods 15: 314-325

Yang B, Qi H, Gu Z, Zhang H, Chen W, Chen H, Chen YQ (2017) Characterization of the triple-component linoleic acid isomerase in Lactobacillus plantarum ZS2058 by genetic manipulation. J Appl Microbiol 123: 1263-1273. https://doi.org/10.1111/jam.13570

Yang B, Gao H, Stanton C, Ross RP, Zhanga H, Chen YQ (2017) Bacterial conjugated linoleic acid production and their applications. Prog Lipid Res 68: 26-36. https://doi.org/10.1016/j.plipres.2017.09.002

Yuce HB, Akbulut N, Ocakli S, Kayir O, Elmastas M (2017) The effect of commercial conjugated linoleic acid products on experimental periodontitis and diabetes mellitus in Wistar rats. Acta Odontol Scand 75: 21-29. https://doi.org/10.1080/00016357.2016.1244355 